\section{Discharge into the community from a mental handicap hospital}

Sir: We would like to relate the findings of a study into the resettlement of ten men with learning difficulties and challenging behaviour into the community from a large hospital for the mentally handicapped. The findings demonstrate the need for specialist care and services in the community for such patients to ensure proper care and prevent re-admission to hospital. The study looked at changes in behaviour, self-care skills and communication skills six weeks after discharge into the community. The mean length of stay in hospital had been 18.2 years and the mean age of the clients was 34.6 years. Each had at one time exhibited challenging behaviours such as self injury, faecal smearing, rectal probing, injury to others, violence to objects and absconding, and each had either moderate or severe learning difficulties. Behaviour, self-care and communication skills were assessed before discharge and six weeks post discharge. Communication skills were unchanged, self-care skills deteriorated and behaviour worsened (continence, self injury, violence to objects and people, absconding and disturbed sleep).

While only a small study it supports the view that maladaptive behaviours increase immediately after discharge into the community. We wonder if others are having similar experiences as our large institutions for the mentally handicapped close.

Frances Foster; M. G. A. IZMETH and KATE CUSHING, Greaves Hall Hospital, Southport, Merseyside PR9 8BP

\section{Telephone follow-up in mental handicap}

Sir: Recently I had to cover the work of a consultant colleague absent for some weeks on account of illness. It was not possible to take over all her community clinics and I had to determine the priorities among her case-load. Newly referred out-patients and patients with continuing problems warranted the most urgent attention. Telephone communication with the patients or their carers proved helpful in decision-making.

The convenience of a telephone follow-up practice makes it useful in routine follow-up cases, especially where the carers are responsible and dependable. Attendances at clinics can be made less frequent, saving carer's time and expense, and also reducing the time the patient has to take off from day care centres or work.

A corollary to the telephone follow-up is the need to have a reciprocal 'Helpline' number which patients and carers can use. A pleasing result of the calls was that carers expressed satisfaction that somebody was concerned enough to get in touch with them.

Douglas A. SPENCER, Park House, Meanwood Park Hospital, Leeds LS6 4QB

\section{Community legislation: is it psychiatrists who should be committed?}

Sir: I take issue with Drs Pierides' \& Casey's grounds for rejection of a community treatment order (CTO) (Psychiatric Bulletin, 1993, 17, 300). They argue a CTO would be "unenforceable", as guardianship is. In the same issue (p. 276) Symonds describes two cases where the committed use of guardianship facilitated successful treatment and improved compliance. Guardianship is not widely used because professionals are unfamiliar with it, not because it is "unenforceable".

Pierides \& Casey go on to say "compulsory treatment in the community is . . . unacceptable to the patient and to the clinical team" and support Professor Sims' rejection of scenarios involving injections "on the kitchen table". Forced administration of injections is never acceptable to the patient whatever the location; yet is acceptable to clinical teams in hospital under section 2 or 3 of the Mental Health Act or "common law" when clinical assessment judges it desirable.

Pierides \& Casey describe the virtues of the care programme approach (CPA). In practice when subjects of CPA relapse they are readmitted under section 3 of the Mental Health Act, often after a period of deteriorating mental health and concern to families and professionals alike. CPA has no supervisory 'clout' in legislative terms and is not in itself community care.

Pierides \& Casey conclude "if resources continue to trickle down slowly to these . . . patients whatever legislation is introduced will be ... window dressing". I draw attention to Professor Leonard Stein's view that as psychiatrists we concentrate on episode-oriented care for schizophrenia which has a clinical profile involving both acute relapses and chronic long-term impairment. Unless we commit to both episodic and continuing care to establish a stable community population of patients, funds will continue to be concentrated in episode oriented hospital care.

Why is compulsion only acceptable in hospital? Patients are frequently ready for discharge before the expiry of their section 3 and use of extended leave in the past has been a response to recognition that, faced with poor compliance, some clout is required in supervision. Extended leave affords the opportunity to work with 
patients towards better compliance, an aspect obviously lacking in hospital-based care.

Studies repeatedly demonstrate that patients and their families prefer community treatment and people with serious mental illness are entitled to treatment that will facilitate the lives they choose to lead out of hospital. Moral and financial arguments are inadequate defences against a commitment to community care. We as psychiatrists must be realistic in our management of patients with serious mental illness. I believe this will involve some form of community legislation to treat and supervise at home towards better compliance and quality of life. In this respect it is CPA that is just "window dressing".

KATE LOCKWOOD, Registrar, UMDS/SE Thames Rotation

Sir: In Dr Lockwood's first paragraph, she acknowledges that guardianship has been used successfully in the past. What will community treatment orders (CTOs) achieve that guardianship has not? Further, Dr Lockwood acknowledges that patients are often sent on extended leave while on section 3 , providing clinical teams with the opportunity to continue treating vulnerable patients while in the community. Again, what will CTOs achieve other than further erosion of our patients' civil liberties?

Dr Lockwood is wrong to say that when patients on the care programme approach (CPA) relapse. "they are re-admitted under section 3 of the Mental Health Act (MHA), often after a period of deteriorating mental health". The findings of our research on the CPA (Pierides et al, 1993) show that patients who are carefully supervised after discharge are re-admitted less often, with less use of the MHA, less police involvement and for shorter hospital stays. If additional resources are not identified so as to facilitate what is essentially a blueprint for good community care, then yes, the CPA will be seen to be "window dressing".

We agree with Dr Lockwood that we should commit ourselves to both episodic and continuing care ... this is the point of CPA!

If Dr Lockwood is looking for community 'clout' (sic) she will not get it from yet more legislation. Finally, Dr Lockwood should not be looking for compliance (sic) in her patients but for collaboration. Her suggestions might otherwise be seen by her patients to smack of arrogance.
Pierides. M.. Roy, D. \& Craig. T.K.J. (1993) The Care Programme Approach (Abstract) Preliminary Results One Year After Implementation In An Inner City Hospital. Presented at Community Care: making it work. Institute of Psychiatry. 16 November 1993

M. PIERIDES and C. CASEY, UMDS of Guys \& St Thomas' Hospital, London SE1

\section{SANELINE}

Sir: SANELINE is a national telephone helpline for anyone coping with mental illness, and in the 18 months the line has been open, over 150,000 people have attempted to call. As well as supporting callers through periods of distress, SANELINE volunteers offer practical help from the database which has over 12,000 entries of local mental health services. In May 1994, SANELINE will be taking to the road, and visiting ten major towns and cities to publicise the service to potential callers, service providers and mental health professionals.

Since we have been open, many people have come forward with offers of help. We have over 100 solicitors who have agreed to give $30 \mathrm{~min}$ utes of free legal advice over the telephone, and a growing number of consultant psychiatrists willing to take referrals for second opinions from our callers.

We would very much like to extend this part of our service, and hope to build up a network of psychiatrists around the country.

CARYL WRIGHT, SANELINE Manager, 2nd Floor. 199-205 Old Marylebone Road, London NWI 5QP

\section{Singers from Nottingham}

Sir: Regarding the report of the 4th Annual Scientific Conference for Senior Registrars in Psychiatry from David Castle (Psychiatric Bulletin, 1993, 17, 764), I always knew that I worked in a cultural centre, but not only was Professor Patricia Casey a registrar in Nottingham but the two Irish senior registrars are in fact one a lecturer and one a senior registrar both working in Nottingham. Obviously, all those of you with admirable singing voices should look to a place on the Nottingham Higher Training Scheme.

MIKE HARRIS, Nottingham Healthcare Unit, Mapperley Hospital, Nottingham NG3 6AA 